\title{
The European lightning location system EUCLID - Part 2: Observations
}

\author{
Dieter Roel Poelman ${ }^{1}$, Wolfgang Schulz ${ }^{2}$, Gerhard Diendorfer ${ }^{2}$, and Marina Bernardi ${ }^{3}$ \\ ${ }^{1}$ Royal Meteorological Institute of Belgium, Brussels, Belgium \\ ${ }^{2}$ OVE-ALDIS, Vienna, Austria \\ ${ }^{3}$ CESI - Centro Elettrotecnico Sperimentale Italiano spa, Milan, Italy \\ Correspondence to: Dieter Roel Poelman (dieter.poelman@meteo.be)
}

Received: 27 July 2015 - Published in Nat. Hazards Earth Syst. Sci. Discuss.: 4 September 2015

Revised: 7 December 2015 - Accepted: 8 January 2016 - Published: 2 March 2016

\begin{abstract}
Cloud-to-ground (CG) lightning data from the European Cooperation for Lightning Detection (EUCLID) network over the period 2006-2014 are explored. Mean CG flash densities vary over the European continent, with the highest density of about $6 \mathrm{~km}^{-2} \mathrm{yr}^{-1}$ found at the intersection of the borders between Austria, Italy and Slovenia. The majority of lightning activity takes place between May and September, accounting for $85 \%$ of the total observed CG activity. Furthermore, the thunderstorm season reaches its highest activity in July, while the diurnal cycle peaks around 15:00 UTC. A difference between CG flashes over land and sea becomes apparent when looking at the peak current estimates. It is found that flashes with higher peak currents occur in greater proportion over sea than over land.
\end{abstract}

\section{Introduction}

Numerous ground-based lightning location systems (LLSs) exist to date employing different types of sensors and detection techniques, enabling the user to detect cloud-toground (CG) and/or intra- and inter-cloud electrical activity. As such, it is possible to retrieve not only the geographical and frequency distribution of lightning on a global scale (Jacobson et al., 2006; Keogh et al., 2006; Said et al., 2010, 2013), but detailed information at the level of individual strokes or flashes as well by means of three-dimensional reconstruction of the development of the lightning channel as observed by present-day lightning mapping arrays (LMAs) (Rison et al., 1999; Thomas et al., 2004; van der Velde et al., 2013; Defer et al., 2015). Nevertheless, each LLS has its pros and cons. Whereas networks operating at the very low frequencies (VLFs) are able to detect lightning over large distances with a relatively low amount of sensors, these systems are limited in location accuracy (LA) and detection efficiency (DE) when compared to the LMA performance. On the other hand, LMAs function at very high frequencies (VHFs), thereby restricting the range of observation to very local scales, and they do not detect the ground stroke very well. LLSs operating at low frequencies (LFs) combine the best of both worlds: with baselines of a few hundred of kilometers it is possible to cover countries as well as continents (e.g. Biagi et al., 2007; Nag et al., 2011; Mallick et al., 2014; Schulz et al., 2005; Antonescu and Burcea, 2010; Enno, 2011; Mäkelä et al., 2014), while still retaining a satisfactory level of performance in terms of LA and DE.

While most LLSs provide supplementary information such as polarity and peak current of the lightning discharge, it is the spatial flash incidence that remains the main objective. This continuous interest in the spatial distribution of the lightning flash density $N_{g}$ is not surprising as it is not only of importance for climatological studies, but plays a vital role as well in the risk analysis for protecting structures and electronic systems against damage from lightning impacts to ground (see risk management in accordance with IEC 62305-2). Various studies exist already in Europe, assessing the lightning climatology at regional scales or within country borders. For instance, Finke and Hauf (1996) observed the lightning occurrence in southern Germany and retrieved a mean spatial density of 2.8 strokes $\mathrm{km}^{-2} \mathrm{yr}^{-1}$ using grid cells of $2 \mathrm{~km} \times 2 \mathrm{~km}$ in size and based on a 3year data set. Schulz et al. (2005) found that over a 10- 
year observation period, average flash densities vary between 0.5 and 4 flashes $\mathrm{km}^{-2} \mathrm{yr}^{-1}$ in Austria using a spatial grid resolution of $1 \mathrm{~km} \times 1 \mathrm{~km}$, whereas according to Antonescu and Burcea (2010) the average annual CG lightning density in Romania ranges from 0.34 flash $\mathrm{km}^{-2} \mathrm{yr}^{-1}$ in the east to 3.06 flashes $\mathrm{km}^{-2} \mathrm{yr}^{-1}$ in the south as determined using a $20 \mathrm{~km} \times 20 \mathrm{~km}$ resolution and averaged over three observational years. Poelman (2014) reported average CG flash densities in Belgium retrieved on a $3 \mathrm{~km} \times 3 \mathrm{~km}$ grid varying between 0.3 flash $\mathrm{km}^{-2} \mathrm{yr}^{-1}$ in the west up to 2.4 flashes $\mathrm{km}^{-2} \mathrm{yr}^{-1}$ toward the east of Belgium, with a mean flash density of 0.7 flash $\mathrm{km}^{-2} \mathrm{yr}^{-1}$. The lowest values in Europe are found in the northern Scandinavian countries with average flash densities of about $1 \mathrm{flash} \mathrm{km}^{-2} \mathrm{yr}^{-1}$ in the southwest of Sweden and in Baltic countries, down to 0.01 flash $\mathrm{km}^{-2} \mathrm{yr}^{-1}$ along the coast of Norway (Enno, 2011; Mäkelä et al., 2014) on a $20 \mathrm{~km} \times 20 \mathrm{~km}$ grid. While it is clear that over the European continent flash densities vary from one region to another, it is not straightforward to combine latter studies into one coherent picture due to the different LLSs, observational periods and grid resolutions used, as well as changes in the performance over time for a particular LLS. Another approach to investigate the European lightning density in a more coherent way is by making use of a long-range VLF lightning network. This has been done by Anderson and Klugmann (2014), presenting the observations made by the Met Office Arrival Time Difference Network (ATDnet) over Europe. However, ATDnet's observations contain, similar to other VLF networks, a certain fraction of cloud signals in addition to CG lightning (Jacobson et al., 2006; Poelman et al., 2013b), which has not been accounted for in their analysis. In addition, the spatial distribution of lightning, i.e., CG and cloud lightning, over Europe has been measured by the optical transient detector (OTD) onboard the Orbview-1/Microlab satellite (Christian et al., 2003). Although OTD's measurements are useful in providing the overall spatial behavior over large areas, the absolute lightning density should be interpreted with caution as a result of the moving field of view.

In this paper we report on the cloud-to-ground lightning characteristics over most of Europe based on the observations of the European lightning location system EUCLID. This network combines time-of-arrival (TOA) and direction finding (DF) techniques at LF to geolocate lightning discharges. Figure 1 displays the current sensor locations within the EUCLID network and the region of investigation for the following analyses. The performance of EUCLID has been frequently tested over the years in terms of its location accuracy, detection efficiency and peak current estimation. For the latest in-depth analysis of the performance validation of EUCLID in Europe, the interested reader is referred to Schulz et al. (2015). A description of the treatment of the data and methodology is provided in Sect. 2. Section 3 is reserved to display the temporal and spatial statistics along with an anal-

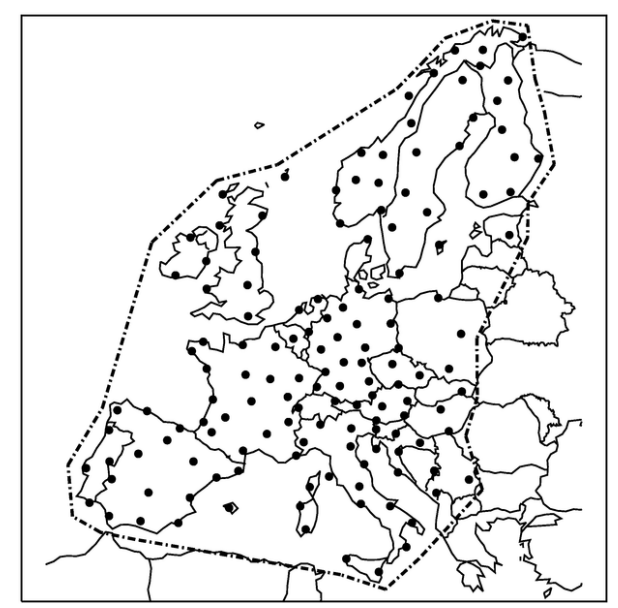

Figure 1. Sensor locations within the EUCLID network. Note that only data within the polygon (dashed-dotted line) is used for quantitative analysis in this work.

ysis of the multiplicity and peak current estimates. We conclude and summarize in Sect. 4.

\section{Data and methodology}

Since the start of EUCLID in 2001, its performance improved gradually over the years. This improvement is attributed to an increased number of sensors contributing to the network, but is also due to the upgrade of the older type of sensors into the newest LS700x sensor technology and by the implementation of advanced processing algorithms (Schulz et al., 2015). Nevertheless, for the purpose of this study it can be assumed that from 2006 onward the improvements to the network in terms of flash detection efficiency and location accuracy will have minimal influence on the outcome presented in the remainder of this paper. This is true, since even though the stroke DE has improved, the flash DE remained rather stable since to detect a flash it is sufficient to identify successfully solely one stroke out of several in a multistroke flash. As such, we opt to use flash data from 2006 until 2014 in this study. In addition to CG detections, EUCLID is able to detect part of the strongest cloud-to-cloud (CC) discharges as well, using the capability of the LS700x sensors. The discrimination between CC and CG discharges is based on peak-to-zero threshold values. Note that in this work we consider each CC signal as an individual CC flash.

Initial CG stroke data are grouped into CG flashes, with individual strokes belonging to a particular flash if $\Delta t<1.5 \mathrm{~s}$ and $\Delta r<10 \mathrm{~km}$, with respect to the time and position of the first stroke in the flash. In addition to the flash duration $\Delta t$, a

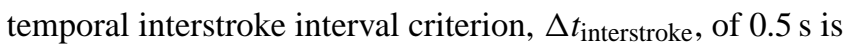
used as well. These grouping criteria overlap well with those used in other studies (e.g. Cummins et al., 1998; Kuk et al., 2011), except for the more relaxed time criterion, compared 

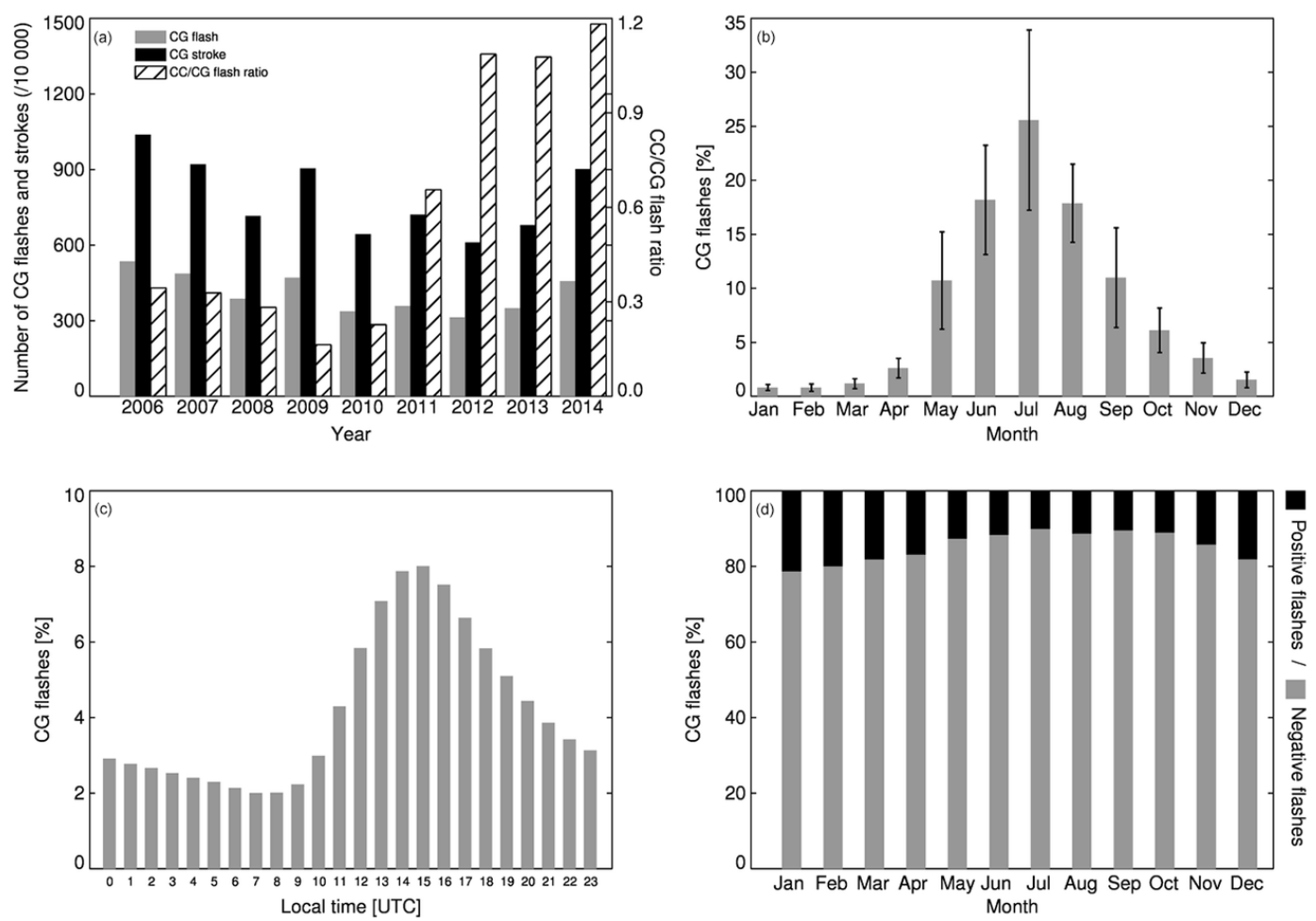

Figure 2. (a) Variation of the annual CG stroke and flash counts, as well as the CC/CG flash ratio, (b) mean monthly flash counts with bars representing the \pm 1 SD (standard deviation), (c) mean diurnal flash counts and (d) mean monthly polarity distribution, based on 2006-2014 EUCLID data.

to a $\Delta t$ of $1 \mathrm{~s}$ what is traditionally used. Since occasionally flashes are observed with a duration exceeding $1 \mathrm{~s}$ (Poelman et al., 2013a), the maximum flash duration $\Delta t$ of $1.5 \mathrm{~s}$ used in this work is justified. The position and peak current of the first return stroke are chosen as the position and peak current of the CG flash, respectively. Note that positive discharges with peak currents smaller than $10 \mathrm{kA}$ are likely to be misclassified as CG strokes when in fact those are more likely to be of intracloud nature (Cummins et al., 1998; Wacker and Orville, 1999a, b; Jerauld et al., 2005; Orville et al., 2002; Biagi et al., 2007). Therefore, we opt to remove them from the data set. About $5 \%$ of all the flashes that are removed in this way are single stroke positives. In addition, after removing those particular positive strokes in a multiple-stroke flash, about $3 \%$ of the flashes remain to be bipolar flashes. Because often positive cloud strokes are wrongly grouped to negative CG flashes, those bipolar flashes have been removed as well, such that the final flash data set contains only flashes with strokes of the same sign belonging to a particular flash.

Geographical plots are presented with a spatial resolution of $20 \mathrm{~km} \times 20 \mathrm{~km}$, or is stated otherwise. Note that this adopted grid size is much larger than the assumed LA of EUCLID within Europe and is therefore appropriate for this study. Moreover, it can be demonstrated that an uncertainty in flash density of less than $20 \%$ at $90 \%$ confidence level is obtained, when the minimum requirements are satisfied by following equation:

$N_{g} \times T_{\text {obs }} \times A_{\text {cell }} \geq 80$,

with $T_{\text {obs }}$ the observation period and $A_{\text {cell }}$ the grid cell area expressed in years and $\mathrm{km}^{2}$, respectively (Diendorfer, 2008). Hence, with an observation period of 9 years and a grid cell area of $400 \mathrm{~km}^{2}$, regions with flash densities down to 0.02 flashes per $\mathrm{km}^{2}$ per year are still accurately depicted in this way. Spatial distribution maps of, for example, the flash density or peak current are then obtained by summing the relevant parameter and dividing it by the amount of flashes observed per grid cell. Considering the excellent flash DE, no correction factor has been applied to the flash data in the course of this study.

\section{Results and analysis}

\subsection{Temporal statistics}

Figure 2a plots the temporal distribution of the CG stroke and flash count over the years, observed within the polygon displayed in Fig. 1. As expected, the CG activity experiences a natural annual variability, with an observed minimum of $\sim 31 \times 10^{5}$ flashes in 2012 , increasing up to $\sim 54 \times 10^{5}$ 

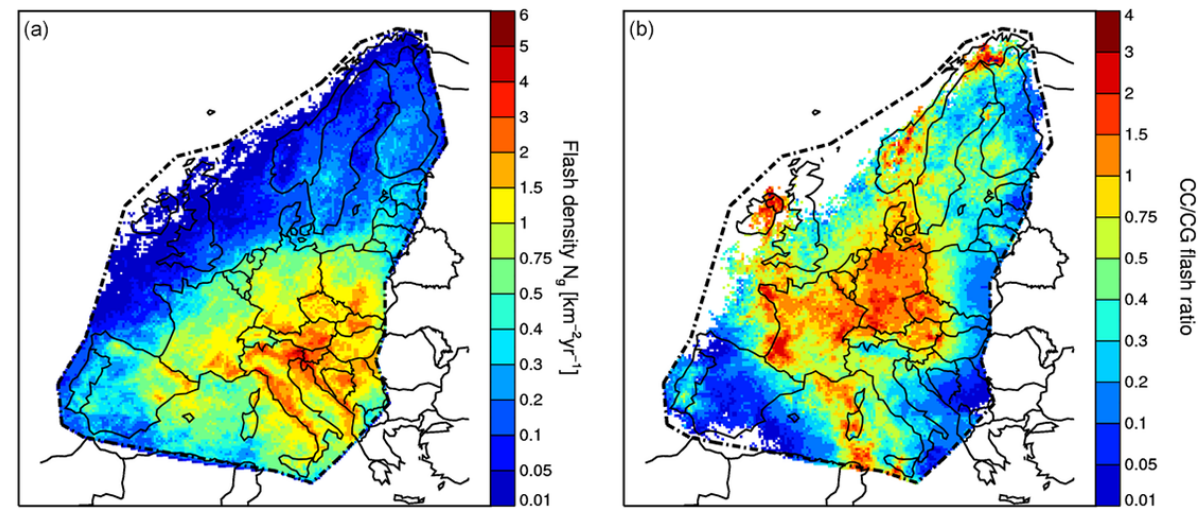

Figure 3. (a) Mean annual CG flash density $\left[\mathrm{km}^{-2} \mathrm{yr}^{-1}\right]$, and (b) CC/CG flash density ratio, based on 2006-2014 EUCLID data and adopting a spatial resolution of $20 \mathrm{~km} \times 20 \mathrm{~km}$.

flashes in 2006. Annual variations are found as well in other parts of the globe and are attributed to the natural variability of the climate (Ghil, 2002). In addition, the CC / CG flash ratio is indicated as well. One notices a sharp increase in the CC/CG flash ratio from 2011 onward, which is related to the introduction of new firmware on all the LS700x sensors in the network.

The distribution of the mean monthly flash count, including the respective $\pm 1 \mathrm{SD}$ (standard deviations), is shown in Fig. 2b. In the same way as the amount of detections per month are expressed in percentages with respect to the total activity, a similar conversion factor has been applied to the SD to translate it into percentages. Nearly $85 \%$ of all the detected flashes occur between May and September, with a clear peak in July. On the other hand, the winter months account only for $3 \%$ of the observed lightning activity in Europe. This typical seasonal cycle is related to solar heating which peaks in European summer and favors the onset of convective storms, while on the other hand winter thunderstorms are mostly associated with the movement of cold fronts.

Figure $2 \mathrm{c}$ indicates the diurnal flash count as a function of local time, with a time resolution of $1 \mathrm{~h}$ and expressed in terms of percentage of the total CG flash activity. A minimum is observed at 07:00 UTC followed by a steady increase up to the maximum point in the afternoon at 15:00 UTC. As expected, the diurnal flash count follows the diurnal temperature cycle, with about $50 \%$ of the activity taking place between 12:00 and 18:00 UTC. The lower observed activity in the morning hours is inherent to the reduced occurrence of convective development due to solar heating of the ground and/or the atmospheric boundary layer. The overall diurnal behavior of CG flash counts in Europe overlaps well with those in other parts of the globe (Blakeslee et al., 2014).

Figure 2d displays the mean polarity distribution in Europe as a function of month. Overall, about $15 \%$ of the observed flashes are positive, with an observed increase of positive flashes during the winter months. This pronounced increase could be related to a decrease in height of winter thunderstorms, lowering the upper positive charge of the cloud (Pinto et al., 1999), and it is similar to the reports based on NLDN data (Orville and Huffines, 1999; Orville, 2001) in the US.

\subsection{Flash density}

Figure 3a plots the 9-year mean annual ground flash density derived from roughly 37 million CG flashes. The highest densities are found to be located over land, with most of the lightning detected at the intersection of the borders between Austria, Italy and Slovenia, experiencing a flash density of $\sim 6$ flashes $\mathrm{km}^{-2} \mathrm{yr}^{-1}$ at $20 \mathrm{~km} \times 20 \mathrm{~km}$ resolution. In general, densities vary between 0.5 and 4 flashes $\mathrm{km}^{-2} \mathrm{yr}^{-1}$ over mainland Europe, while it is clear that the Scandinavian countries and the UK experience the least amount of lightning activity in Europe. This observed spatial distribution overlaps well with the results as observed previously over Europe by the satellite-based Optical Transient Detector (OTD; Christian et al., 2003) and the ground-based longrange UK Arrival Time Difference Network (ATDnet) (Anderson and Klugmann, 2014), although the extent of densities may differ to some degree. In Fig. 3b, the geographical spread of the CC/CG flash ratio is plotted. This distribution does not resemble the true CC/CG occurrence over $\mathrm{Eu}-$ rope, but is merely a measure of the capability of the LS700x sensors to detect CC signals. This is true, since the highest CC/CG ratios are found in areas where the baselines between LS700x sensors are small. For instance, Germany and some parts of France experience a high CC / CG ratio up to a factor of 4 , whereas over Spain, containing only a few LS700x sensors at present, EUCLID is not efficient to detect $\mathrm{CC}$ signals at this moment.

Figure 4 shows the monthly flash density distribution. For this, the average densities for each month are calculated over the observation period of 9 years and subsequently extrapolated to entire years to attain $\mathrm{km}^{-2} \mathrm{yr}^{-1}$ units. In this way, the densities in Fig. 4 can be directly intercompared to the 


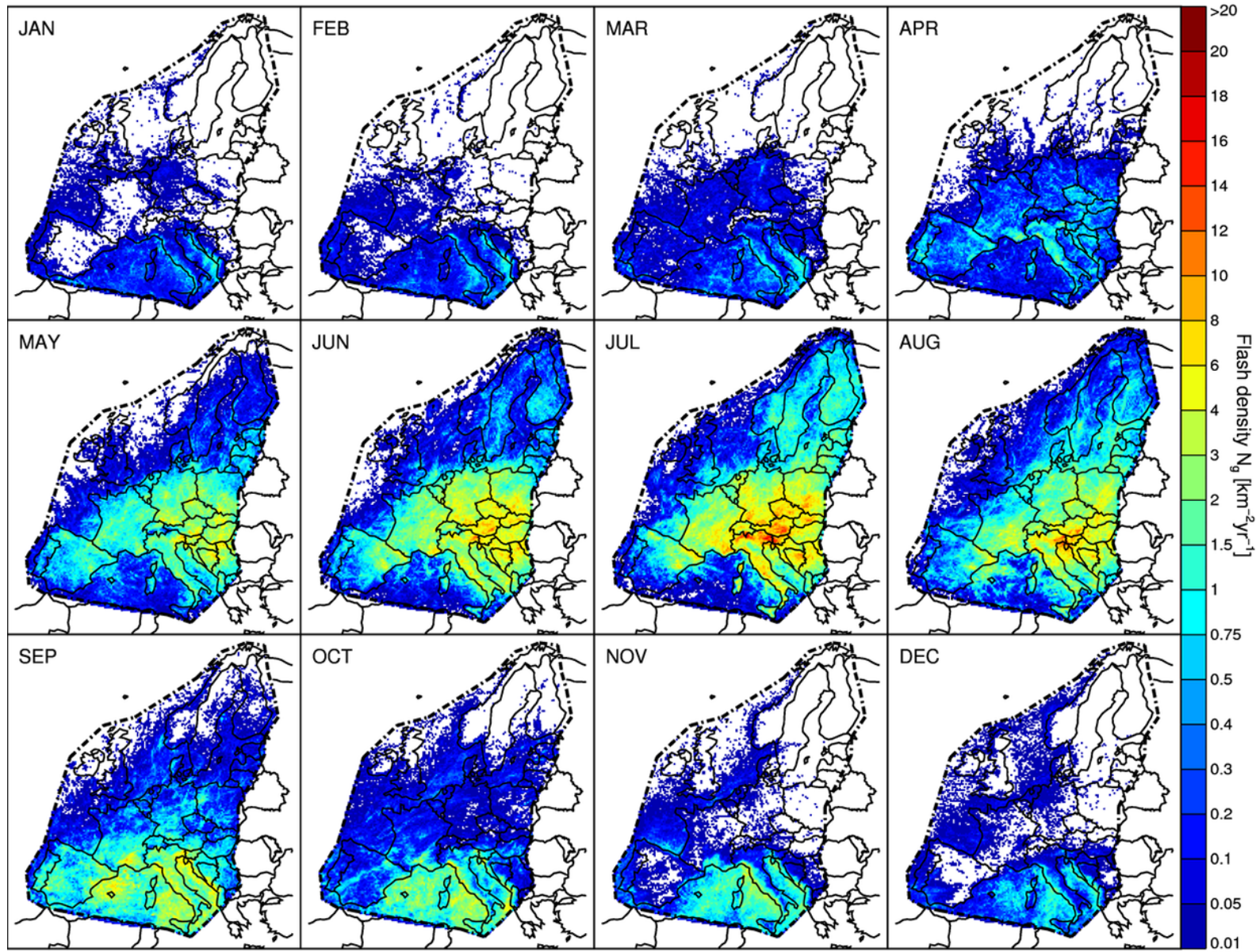

Figure 4. Monthly variability of flash density $N_{g}\left[\mathrm{~km}^{-2} \mathrm{yr}^{-1}\right]$, based on 2006-2014 EUCLID data and adopting a spatial resolution of $20 \mathrm{~km} \times 20 \mathrm{~km}$.

mean annual ground flash density in Fig. 3a. One notices that the main lightning activity over the Mediterranean and coastal sea occurs during the months September-March. This is a result of the residual heat stored in the upper water layers from the previous summer, inducing convective development. Contrary to the sea, over land the majority of the activity kicks in during the summer months starting around May and ending in September, where land surface heating drives the onset of convection.

\subsection{Multiplicity}

The term "multiplicity" is used here to indicate the total number of strokes per flash. Its value depends strongly on the stroke DE and adopted algorithm to group strokes into flashes. Figure 5a plots the percentage of amount of strokes detected within a single negative and positive flash. The observed percentage of single-stroke negative flashes is $55 \%$, and increases up to $95 \%$ for positive flashes. $85 \%$ of all negative flashes have been observed with three strokes or less. We find a mean multiplicity of 2.1 and 1.1 for nega- tive and positive flashes, respectively. This is an underestimation when compared to ground truth recordings. For instance, based on ground truth recordings in Belgium, Poelman et al. (2013a) found a mean multiplicity for negative flashes of 3.7, while similar multiplicities are found in comparable ground truth studies at different regions (Rakov and Huffines, 2003; Saraiva et al., 2010; Ballarotti et al., 2012). Likewise, the high percentage of single stroke negative flashes is an overestimation with respect to ground truth observations, reporting in general values between 20 and $40 \%$ (Fleenor et al., 2009; Biagi et al., 2007; Poelman et al., 2013a). This overestimation of the amount of single-stroke flashes is observed by many other ground-based networks as well (Rakov and Huffines, 2003; Schulz et al., 2005; Poelman et al., 2013a) and can be related to the fact that first strokes tend to be, in general, more easily detected by an LLS because of its higher peak current compared to the subsequent strokes. Additionally, outliers and misclassified cloud pulses which are not in time and distance close to another stroke further increase the percentage of single-stroke flashes. 

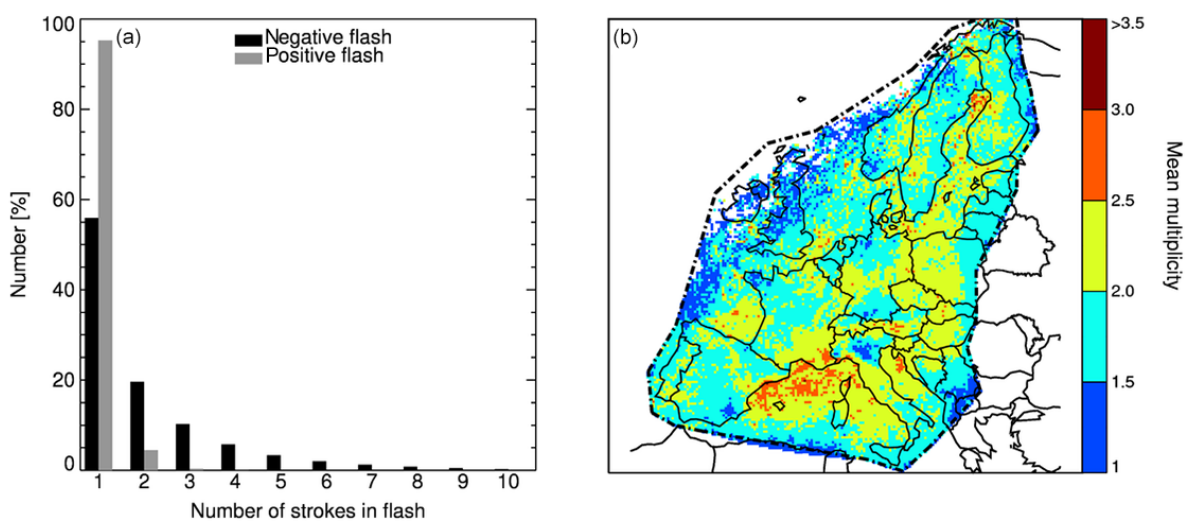

Figure 5. (a) Histogram of the percentage of strokes per flash for negative (black) and positive (grey) flashes, and (b) multiplicity distribution of negative flashes, based on 2006-2014 EUCLID data and adopting a spatial resolution of $20 \mathrm{~km} \times 20 \mathrm{~km}$.
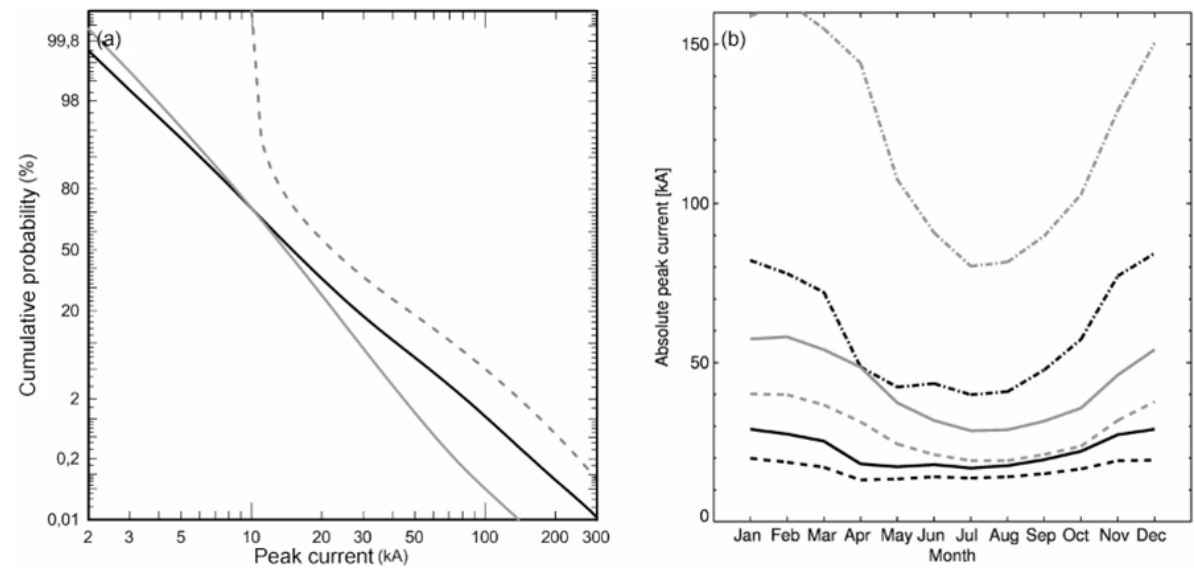

Figure 6. (a) Cumulative statistical distribution of return-stroke peak currents for negative first strokes (black solid), negative subsequent (grey solid), and positive first strokes (grey dashed). (b) Peak current distribution as a function of month for negative (black) mean (solid), median (dashed), 95th percentile (dashed-dotted) and for positive (grey) mean (solid), median (dashed), 95th percentile (dashed-dotted) strokes.

Figure 5b plots the spatial distribution of the multiplicity of negative flashes. The minimum is found at the limits of EUCLID's boundary and is a consequence of a drop in detection efficiency where only the strongest strokes within a flash tend to be detected. The spatial variance in Fig. 5b can be attributed to orography, cloud altitude and latent heat of the surface, intrinsic to specific areas. Note that a negative $C G$ flash with a maximum multiplicity of 49 has been recorded. The latter was a flash to a tall radio and TV tower in the south of Austria, at the border of Italy and Slovenia. The overall highest multiplicities are found over the southern part of the Bay of Biscay, the Adriatic Sea and the Mediterranean Sea. This observed increase in multiplicity in latter regions could be related to the augmented estimated peak currents, as will be discussed in Sect. 3.4. Since strokes with higher peak currents are easier detectable by an LLS, it can explain the multiplicity distribution in Fig. 5 b.

\subsection{Lightning peak current}

Peak current estimates by EUCLID have been compared against direct measurements, made possible by dedicated instruments installed on the Gaisberg tower in Austria (Diendorfer et al., 2009). One can deduce a median peak current estimation error of $4 \%$ compared to the measured peak currents at the Gaisberg tower (Schulz et al., 2015).

Mean/median peak current for negative and positive first strokes is $-18.6 /-15.0 \mathrm{kA}$ and $+34.5 /+22.2 \mathrm{kA}$, respectively. In absolute terms, positive first strokes have higher peak currents compared to their negative counterparts. Subsequent negative strokes have mean/median peak currents of $-15.2 /-14.0 \mathrm{kA}$, and are hence lower compared to negative first strokes.

Figure 6a shows the cumulative statistical distribution of return stroke peak currents for negative first strokes, negative subsequent strokes, and positive strokes. It enables the viewing of the percentage of peak currents exceeding a par- 

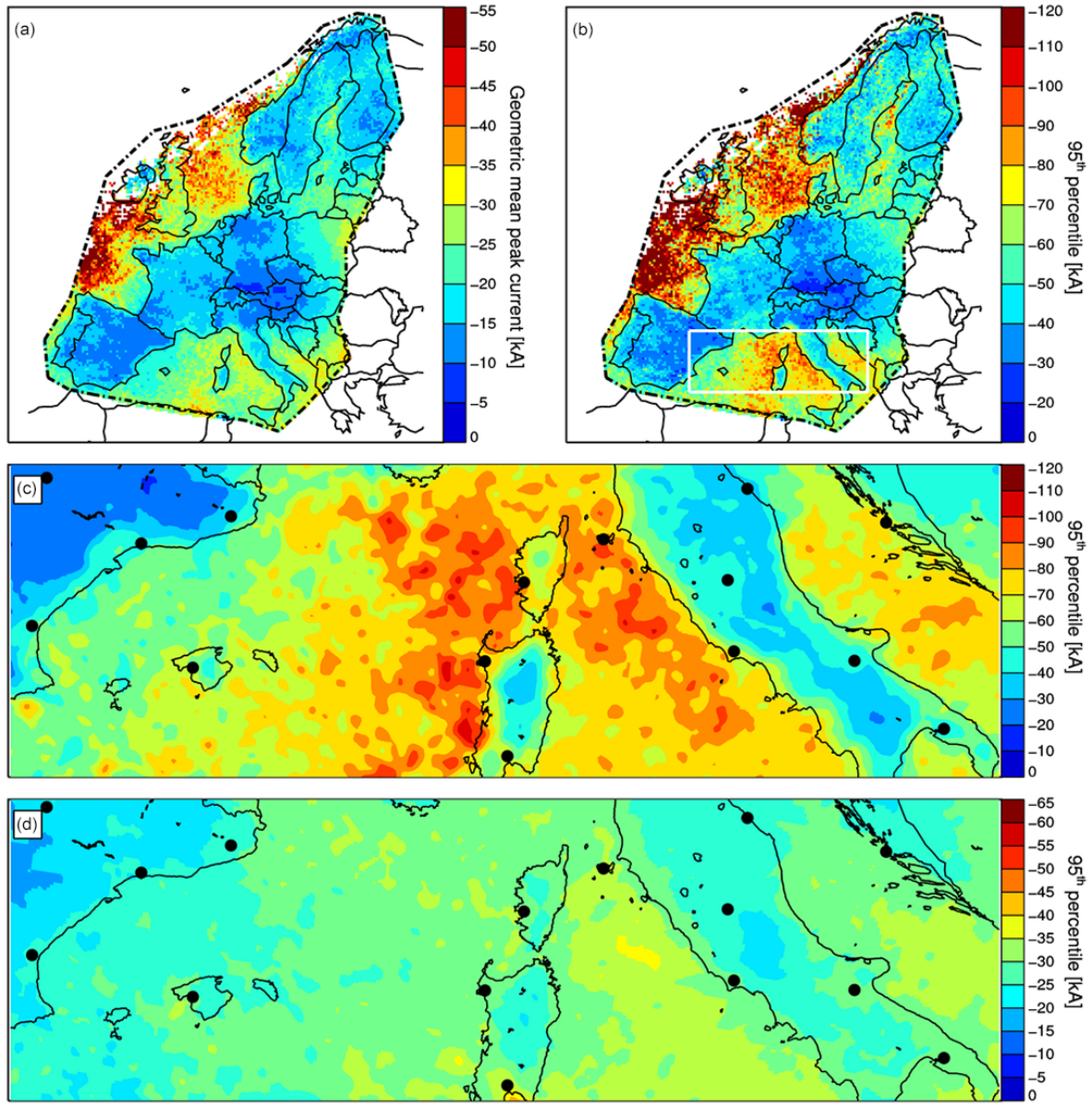

Figure 7. Distribution of (a) geometric mean, and (b) 95 th percentile of the peak current [kA] from first strokes in negative flashes, based on 2006-2014 EUCLID data and adopting a spatial resolution of $20 \mathrm{~km} \times 20 \mathrm{~km}$. (c) Zoomed-in view as outlined by the white box in (b), smoothed by a Gaussian filter for clarity. (d) Same as (c), but for subsequent strokes. In addition, the sensor locations are indicated in (c) and (d).

ticular value on the horizontal logarithmic axis. The vertical axis is chosen in such a way so that a Gaussian (normal) cumulative distribution appears as a slanted straight line. One deduces that about $50 \%$ of the negative first and subsequent strokes exhibit peak currents larger than $15 \mathrm{kA}$, whereas this increases to $22 \mathrm{kA}$ for positive first strokes. In general one finds that negative first strokes have higher peak currents compared to the subsequent negative strokes, but is lower than the peak currents deduced for positive strokes. The respective 95,50 and $5 \%$ values following the peak current distributions are summarized in Table 1.

Figure $6 \mathrm{~b}$ plots the monthly distribution of the mean, median and 95th percentile peak current for negative and positive strokes. It is found that during the summer months the lowest values are found, with higher estimated peak currents observed toward the end/beginning of the year. Such a behavior has also been demonstrated in the US (Brook, 1992) and is believed to be related to the observation that electric-field initiating lightning during winter is greater than during sum-
Table 1. Peak current cumulative statistical distribution values.

\begin{tabular}{lccc}
\hline & \multicolumn{3}{c}{$\begin{array}{c}\text { Percentage exceeding } \\
\text { tabulated value }\end{array}$} \\
\cline { 2 - 4 } Peak current [kA] & $95 \%$ & $50 \%$ & $5 \%$ \\
\hline First neg. strokes & 4 & 15 & 58 \\
Subseq. neg. strokes & 5 & 14 & 35 \\
First pos. strokes & 11 & 22 & 100 \\
\hline
\end{tabular}

mer. Hence, discharges produced during the winter tend to exhibit more energetic discharges with higher peak currents (Brook, 1992).

Figure $7 \mathrm{a}$ and $\mathrm{b}$ display the spatial distribution of the geometric mean and 95th percentile of estimated peak current currents in negative flashes. Over large parts of mainland Europe, the mean values range between -20 and $-5 \mathrm{kA}$. However, a clear transition between land and sea alongside the Italian and Sardinian coast and the Adriatic Sea is noticed. 

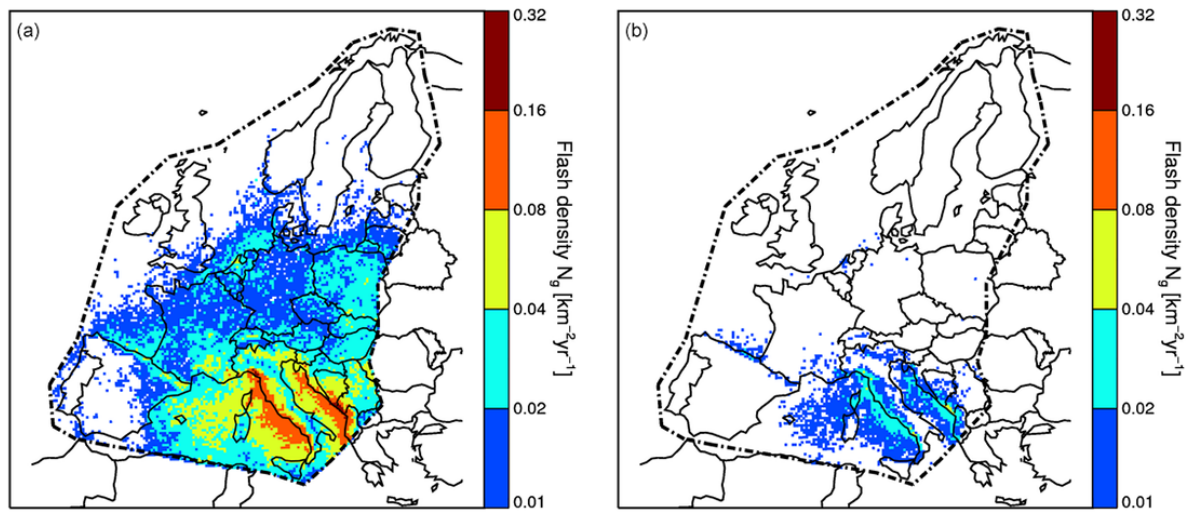

Figure 8. Mean annual flash density $\left[\mathrm{km}^{-2} \mathrm{yr}^{-1}\right]$ of negative CG flashes with estimated absolute peak current above (a) $75 \mathrm{kA}$ and (b) $125 \mathrm{kA}$.

This becomes more obvious when looking at the 95th percentile in Fig. 7b. Figure 7c zooms in on a particularly interesting region in the Mediterranean Sea, indicated by the white box in Fig. 7b. This region in particular is covered well by multiple EUCLID sensors positioned inland and along the coast of France and Italy. In addition, one sensor is located in the southwest of the Corsica, while two others are positioned in the west and southwest of Sardinia. Even though the observed change in peak current behavior between land and sea is in line with previous findings along the coast of, for example, France (Seity et al., 2001) and the US by the Global Lightning Dataset (GLD360) (Said et al., 2013) and World Wide Lightning Location Network (WWLLN) networks (Hutchins et al., 2013), one can speculate that it is an artifact of the change in conductivity which is not accounted for by the central processor. This is simply due to an instrumentation effect, or results from sensor coverage issues over sea. However, Corsica and Sardinia exhibit a decrease in peak current magnitude as well compared to the surrounding water mass, while being well covered by lightning sensors. This strengthens the hypothesis that the observed peak current behavior is real. The decrease is somewhat more pronounced over Sardinia since it is about three times larger than Corsica. The same behavior, although less obvious, holds for the subsequent strokes, as evidenced in Fig. 7d. In addition, a similar trend between land and sea lightning is found as well when looking at the CG flash density of negative flashes with estimated peak currents larger than 75 and $125 \mathrm{kA}$, plotted in Fig. 8a and b, respectively. Overall, it is striking that flashes with higher peak currents primarily occur in greater numbers over sea than on the mainland. Furthermore, the flash density for flashes with peak currents larger than $75 \mathrm{kA}$ is lower over Sardinia by a factor of about 2 compared to the flash density in the sea surrounding it. Likewise, the amount of flashes with peak currents greater than $125 \mathrm{kA}$ over Sardinia is negligible, whereas those flashes appear in the nearby sea.

\section{Summary}

Due to the variable nature of lightning occurrence from year to year, reliable insights into lightning activity and parameters can only be achieved when based on large amounts of data. In this work, a total of 32 million CG flashes recorded between 2006 and 2014 are used to analyze the spatial and temporal characteristics within the EUCLID domain.

It is found that the lightning activity primarily takes place between May and September, accounting for about $85 \%$ of the total observed lightning activity. From October onwards, the activity over mainland Europe decreases gradually, while on the other hand the activity over sea, especially the Mediterranean Sea, increases in magnitude as a result of residual heat stored in the water. The thunderstorm season reaches its peaks in July within the complete EUCLID domain. As regards the average diurnal flash counts, those are lowest during the morning hours, followed by a continuous increase from 10:00 UTC up to 15:00 UTC. However, it is worth noting that this diurnal behavior combines observations of lightning activity both over land, sea and even different climates such as the Mediterranean, Scandinavian, and Alpine region. It is thus highly possible that those particular regions exhibit particular features that are removed when averaging over the EUCLID domain.

Average annual ground flash densities vary from less than 0.01 flash $\mathrm{km}^{-2} \mathrm{yr}^{-1}$ in northern Scandinavia to a maximum of about 6 flashes $\mathrm{km}^{-2} \mathrm{yr}^{-1}$ at the intersection of the borders between Austria, Italy and Slovenia, based on a spatial grid resolution of $20 \mathrm{~km} \times 20 \mathrm{~km}$. Between the aforementioned extreme values, a multitude of different flash densities exist within the EUCLID domain, with in general higher values in the east.

It is found that the average absolute peak current of all detected strokes display a monthly dependency, with the largest estimated peak currents observed between November and March. Moreover, a clear discrepancy is noticed between the observed peak current distribution over land and sea, favor- 
ing higher peak current flashes over sea. For the first time, this effect has been demonstrated not only to occur along the coast but in addition over Corsica and Sardinia. This can explain as well the higher multiplicity observed in the Mediterranean sea, since individual strokes with higher peak currents tend to be more easily detected.

Acknowledgements. The authors are grateful for the support from all the EUCLID members and thank the referees for their very helpful comments.

Edited by: A. Mugnai

Reviewed by: S. Soula and one anonymous referee

\section{References}

Anderson, G. and Klugmann, D.: A European lightning density analysis using 5 years of ATDnet data, Nat. Hazards Earth Syst. Sci., 14, 815-829, doi:10.5194/nhess-14-815-2014, 2014.

Antonescu, B. and Burcea, S.: A cloud-to-ground lightning climatology for Romania, Mon. Weather Rev., 138, 579-591, doi:10.1175/2009MWR2975.1, 2010.

Ballarotti, M. G., Medeiros, C., Saba, M. M. F., Schulz, W., and Pinto Jr., O.: Frequency distributions of some parameters of negative downward lightning flashes based on accurate-stroke-count studies, J. Geophys. Res., 117, D06112, doi:10.1029/2011JD017135, 2012.

Biagi, C. J., Cummins, K. L. Kehoe, K. E., and Krider, E. P.: National Lightning Detection Network (NLDN) performance in southern Arizona, Texas, and Oklahoma in 2003-2004, J. Geophys. Res., 112, D05208, doi:10.1029/2006JD007341, 2007.

Blakeslee, R. J., Mach, D. M., Bateman, M. G., and Bailey, J. C.: Seasonal variations in the lightning diurnal cycle and implications for the global electric circuit, Atmos. Res., 135-136, 228243, 2014.

Brook, M.: Breakdown of electric fields in winter storms, Res. Lett. Atmos. Elect., 12, 47-52, 1992.

Christian, H. J., Blakeslee, R. J., Boccippio, D. J., Boeck, W. L., Buechler, D. E., Driscoll, K. T., Goodman, S. J., Hall, J. M., Koshak, W. J., Mach, D. M., and Stewart, M. F.: Global frequency and distribution of lightning as observed from space by the Optical Transient Detector, J. Geophys. Res., 108, 1-15, 2003.

Cummins, K., Murphy, M., Bardo, E., Hiscox, R., Pyle, W. L., and Pifer, A.: A combined TOA/MDF technology upgrade of the U.S. National Lightning Detection Network, J. Geophys. Res., 103, 9035-9044, 1998.

Defer, E., Pinty, J.-P., Coquillat, S., Martin, J.-M., Prieur, S., Soula, S., Richard, E., Rison, W., Krehbiel, P., Thomas, R., Rodeheffer, D., Vergeiner, C., Malaterre, F., Pedeboy, S., Schulz, W., Farges, T., Gallin, L.-J., Ortéga, P., Ribaud, J.-F., Anderson, G., Betz, H.-D., Meneux, B., Kotroni, V., Lagouvardos, K., Roos, S., Ducrocq, V., Roussot, O., Labatut, L., and Molinié, G.: An overview of the lightning and atmospheric electricity observations collected in southern France during the HYdrological cycle in Mediterranean EXperiment (HyMeX), Special Observa- tion Period 1, Atmos. Meas. Tech., 8, 649-669, doi:10.5194/amt8-649-2015, 2015.

Diendorfer, G.: Some comments on the achievable accuracy of local ground flash density values, Proc. 29th Int. Conf. on Lightning Protection, Uppsala, Sweden, 6 pp., 2008.

Diendorfer, G., Pichler, H., and Mair, M.: Some parameters of negative upward-initiated lightning to the Gaisberg tower (20002007), IEEE Trans. Electromagn. Compat., 51, 443-452, 2009.

Enno, S. E.: A climatology of cloud-to-ground lightning over Estonia, 2005-2009, Atmos. Res., 100, 310-317, 2011.

Finke, U. and Hauf, T.: The characteristics of lightning occurrence in southern Germany, Beitr. Phys. Atmos., 69, 361-374, 1996.

Fleenor, S. A., Biagi, C. J., Cummins, K. L., Krider, E. P., and Shao, X.-M.: Characteristics of cloud-to-ground lightning in warmseason thunderstorms in the central Great Plains, Atmos. Res., 91, 333-352, doi:10.1016/J.atmosres.2008.08.011, 2009.

Ghil, M.: Natural climate variability. Encyclopedia of global environmental change, in: Volume 1: The Earth System: physical and chemical dimensions of global environmental change, edited by: MacCracken, M. C. and Perry, J. S., John Wiley \& Sons, Ltd, Chichester, 2002.

Hutchins, M. L., Holzworth, R. H., Virts, K. S., Wallace, J. M., and Heckman, S.: Radiated VLF energy differences of land and oceanic lightning, Geophys. Res. Lett., 40, 2390-2394, doi:10.1002/grl.50406, 2013.

Jacobson, A. R., Holzworth, R., Harlin, J., Dowden, R., and Lay, E.: Performance assessment of the World Wide Lightning Location Network (WWLLN), using the Los Alamos Sferic Array (LASA) as ground truth, J. Atmos. Ocean. Tech., 23, 1082-1092, 2006.

Jerauld, J., Rakov, V. A., Uman, M. A., Rambo, K. J., Jordan, D. M., Cummins, K. L., and Cramer, J. A.: An evaluation of the performance characteristics of the U.S. National Lightning Detection Network in Florida using rocket-triggered lightning, J. Geophys. Res., 110, D19106, doi:10.1029/2005JD005924, 2005.

Keogh, S. J., Hibbett, E., Nash, J., and Eyre, J.: The Met Office Arrival Time Difference (ATD) system for thunderstorms detection and lightning location, Forecasting Research Tech. Rep. 488, Numerical Weather Prediction, Met Office, UK, 22 pp., 2006.

Kuk, B. J., Kim, H. I., Ha, J. S., and Lee, H. K.: Intercomparison study of cloud-to-ground lightning flashes observed by KARITLDS and KLDN at South Korea, J. Appl. Meteorol. Clim., 50, 224-232, 2011.

Mäkelä, A., Enno, S. E., and Haapalainen, J.: Nordic lightning information system: thunderstorm climate of northern Europe for the period 2002-2011, Atmos. Res., 139, 46-61, 2014.

Mallick, S., Rakov, V. A., Hill, J. D., Ngin, T., Gamerota, W. R., Pilkey, J. T., Biagi, C. J., Jordan, D. M., Uman, M. A., Cramer, J. A., and Nag, A.: Performance characteristics of the NLDN for return strokes and pulses superimposed on steady currents, based on rocket-triggered lightning data acquired in Florida in 2004-2012, J. Geophys. Res.-Atmos., 119, 38253856, doi:10.1002/2013JD021401, 2014.

Nag, A., Mallick, S., Rakov, V. A., Howard, J., Biagi, C. J., Hill, D., Uman, M. A., Jordan, D. M., Rambo, K. J., Jerauld, J., DeCarlo, B. A., Cummins, K. L., and Cramer, J. A.: Evaluation of U.S. National Lightning Detection Network performance characteristics using rocket-triggered lightning data acquired in 2004-2009, J. Geophys. Res., 116, D02123, doi:10.1029/2010JD014929, 2011. 
Orville, R. E.: Cloud-to-ground lightning in the United States: NLDN results in the first decade, 1989-98, Mon. Weather Rev., 129, 1179-1193, 2001.

Orville, R. E. and Huffines, G. R.: Lightning ground flash measurements over the contiguous United States: 1995-97, Mon. Weather Rev., 127, 2693-2703, 1999.

Orville, R. E., Huffines, G., Burrows, W., Holle, R., and Cummins, K.: The North American Lightning Detection Network (NLDN) - First results: 1998-2000, Mon. Weather Rev., 130, 2098-2108, 2002.

Rakov, V. A. and Huffines, G. R.: Return-Stroke Multiplicity of Negative Cloud-to-Ground Lightning Flashes, J. Appl. Meteorol., 42, 1455-1462, 2003.

Rison, W., Thomas, R. J., Krehbiel, P. R., Hamlin, T., and Harlin, J.: A GPS-based three-dimensional lightning mapping system: initial observations in central New Mexico, Geophys. Res. Lett., 26, 3573-3576, 1999.

Pinto, O., Jr., Pinto, I. R. C. A., Gomes, M. A. S. S., Vitorello, I., Padilha, A. L., Diniz, J. H., Carvalho, A. M., and Filho, A. C.: Cloud-to-ground lightning in southeastern Brazil in 1993: 1. Geographical distribution, J. Geophys. Res., 104, 31369-31379, doi:10.1029/1999JD900800, 1999.

Poelman, D. R.: A 10-year study on the characteristics of thunderstorms in Belgium based on cloud-to-ground lightning data, Mon. Weather Rev., 142, 4839-4849, 2014.

Poelman, D. R., Schulz, W., and Vergeiner, C.: Performance characteristics of distinct lightning detection networks covering Belgium, J. Atmos. Ocean. Tech., 30, 942-951, doi:10.1175/JTECH-D-12-00162.1, 2013a.

Poelman, D. R., Honoré, F., Anderson, G., and Pedeboy, S.: Comparing a regional, subcontinental, and long-range lightning location system over the Benelux and France, J. Atmos. Ocean. Tech., 30, 2394-2405, doi:10.1175/JTECH-D-12-00263.1, $2013 \mathrm{~b}$.

Said, R. K., Inan, U. S., and Cummins, K. L.: Long-range lightning geolocation using a VLF radio atmospheric waveform bank, J. Geophys. Res., 115, D23108, doi:10.1029/2010JD013863, 2010 .
Said, R. K., Cohen, M. B., and Inan, U. S.: Highly intense lightning over the oceans: Estimated peak currents from global GLD360 observations, J. Geophys. Res.-Atmos., 118, 69056915, doi:10.1002/jgrd.50508, 2013.

Saraiva, A. C. V., Saba, M. M. F., Pinto Jr., O., Cummins, K. L., Krider, E. P., and Campos, L. Z. S.: A comparative study of negative cloud-to-ground lightning characteristics in São Paulo (Brazil) and Arizona (United States) based on high-speed video observations, J. Geophys. Res., 115, D11102, doi:10.1029/2009JD012604, 2010.

Schulz, W., Cummins, K., Diendorfer, G., and Dorninger, M.: Cloud-to-ground lightning in Austria: A 10-year study using data from a lightning location system, J. Geophys. Res., 110, D09101, doi:10.1029/2004JD005332, 2005.

Schulz, W., Diendorfer, G., Pedeboy, S., and Poelman, D. R.: The European lightning location system EUCLID - Part 1: Performance analysis and validation, Nat. Hazards Earth Syst. Sci., 16, 595-605, doi:10.5194/nhess-16-595-2016, 2016.

Seity, Y., Soula, S., and Sauvageot, H.: Lightning and precipitation relationship in coastal thunderstorms, J. Geophys. Res., 106, 22801-22816, doi:10.1029/2001JD00244, 2001.

Thomas, R. J., Krehbiel, P. R., Rison, W., Hunyady, S. J., Winn, W. P., Hamlin, T., and Harlin, J.: Accuracy of the lightning mapping array, J. Geophys. Res., 109, D14207, doi:10.1029/2004JD004549, 2004.

van der Velde, O., and Montanya, J.: Asymmetries in bidirectional leader development of lightning flashes, J. Geophys. Res.Atmos., 118, 13504-13519, doi:10.1002/2013JD020257, 2013.

Wacker, R. and Orville, R.: Changes in measured lightning flash count and return stroke peak current after the 1994 U.S. National Lightning Detection Network Upgrade: 1. Observations, J. Geophys. Res., 104, 2151-2157, 1999a.

Wacker, R. and Orville, R.: Changes in measured lightning flash count and return stroke peak current after the 1994 U.S. National Lightning Detection Network Upgrade: 2. Theory, J. Geophys. Res., 104, 2159-2162, 1999b. 